\title{
Evaluation of the Nutritional Quality of Red and Refined Palm Oils Marketed in Yamoussoukro (Côte d'Ivoire)
}

\author{
Behibolo A. Yoboue1* ${ }^{*}$, Koffi Diallo², Issiaka Diomande, Gnomblesson G. Tiahou ${ }^{3}$, \\ Nogbou E. Assidjo ${ }^{1}$
}

${ }^{1}$ Laboratory of Industrial Synthesis Processes of Environment and New Energies (LAPISEN), Institut National Polytechnique Félix Houphouët-Boigny (INP-HB), Yamoussoukro, Côte d'Ivoire

${ }^{2}$ Laboratory of Nutrition and Food Security (LNSA), Nagui-Abrogoua University, Abidjan, Côte d'Ivoire

${ }^{3}$ Laboratory of Medical Biochemistry, Unit of Training and Medical Research, Alassane Ouattara University (UAO), Bouaké, Côte d'Ivoire

Email: *yobouebantoinette@gmail.com

How to cite this paper: Yoboue, B.A. Diallo, K., Diomande, I., Tiahou, G.G. and Assidjo, N.E. (2022) Evaluation of the Nutritional Quality of Red and Refined Palm Oils Marketed in Yamoussoukro (Côte d'Ivoire). Food and Nutrition Sciences, 13, 97-107.

https://doi.org/10.4236/fns.2022.132010

Received: August 18, 2021

Accepted: February 6, 2022

Published: February 9, 2022

Copyright (c) 2022 by author(s) and Scientific Research Publishing Inc. This work is licensed under the Creative Commons Attribution International License (CC BY 4.0).

http://creativecommons.org/licenses/by/4.0/ (c) (i) Open Access

\begin{abstract}
In order to define the nutritional quality of commercialized red and refined palm oils, palm oil samples conditioned or not with aluminum foils were placed in solar radiation for four weeks. Each week, the levels of peroxides, free and unsaturated fatty acids and then vitamins A and E were determined. From these analyzes, the proportions of peroxides and free fatty acids increased with solar exposure time of the oils. These rates ranged from 0.11 to $24.00 \mathrm{meq}$ $\mathrm{O}_{2} / \mathrm{Kg}$ (peroxides) and from 1.11 to $17.14 \mathrm{KOH} / \mathrm{g}$ (free fatty acids). Also, iodine index levels of palm oils decreased during sun exposure "95.11 - $3.22 \mathrm{~g} \mathrm{I} / 100$ g". In addition, vitamin A and $\mathrm{E}$ losses from palm oil samples increased with exposure time. These losses ranged from $0 \%$ to $94.49 \%$ for vitamin A and from $0 \%$ to $83.42 \%$ for vitamin $\mathrm{E}$ from the day of purchase of oils in the fourth week of sun exposure. However, the deterioration of nutritional quality was greater with red and refined palm oil samples unprotected with aluminum foils than those protected.
\end{abstract}

\section{Keywords}

Nutritional, Quality, Palm Oil

\section{Introduction}

Palm oil, extracted from the fruit pulp of the palm tree (Elaeis guineensis), is today the first source of vegetable fats in the world market. It is a major element of 
food security in Asian and African countries [1]. It is also used as a raw material in the manufacturing industries of various food and cosmetic products. The world's annual palm oil production is about 50 million tonnes, or $39 \%$ of global vegetable oil production. Palm oil has become the most important of vegetable oils, far exceeding soybean, rapeseed and sunflower [2] [3]. It raises many interests in terms of its favourable nutritional contributions for health. Indeed, it provides nutrients such as saturated and unsaturated fatty acids that are important sources of energy for consumers. In addition, palm oil is a good source of antioxidants including tocotrienols, tocopherols, carotenoids and phytosterols with cardioprotective and anticarcinogenic effects [4] [5]. Oil, thanks to its global position and its nutritional richness is of increasing interest. However, its conservation in the markets of tropical countries remains to be desired. Indeed, it is often exposed to solar radiation during the marketing period. This conservation condition could lead to changes in the nutritional quality of these oils and have impacts on the health of the consumer. Thus, the need to provide answers to many concerns about nutritional quality of palm oils in the usual conditions, justifies the present study. This consisted in determining acid, iodine, peroxide index and vitamin $\mathrm{A}$ and $\mathrm{E}$ of red and refined palm oils contents during four weeks of solar exposure, representing maximum time of palm oils sale on Yamoussoukro market.

\section{Materials and Methods}

\subsection{Materials}

The material consists of red and refined palm oil collected from different department of the city of Yamoussoukro ( $6^{\circ} 53^{\prime} 04.7^{\prime \prime}$ North and $5^{\circ} 13^{\prime} 54.9^{\prime \prime}$ Ouest).

\subsection{Methods}

The refined oil samples consist of two types of refined palm oils most consumed in Ivory Coast that we named Hraf 1 and Hraf 2 to avoid any advertising. The study involved 18 samples collected and distributed as follows:

- three (3) samples of red palm oil protected from the light with aluminum foil;

- three (3) samples of refined "Hraf 1" palm oil protected from light with aluminum foil;

- three (3) sample "Hraf 2" refined palm oil samples protected from light with aluminum foil;

- three (3) samples of unprotected red palm oil;

- three (3) unprotected "Hraf 1" refined palm oil samples;

- three (3) samples of unprotected "Hraf 2" refined palm oils.

Each sample is taken from an overall sample by homogenization and reduction of the appropriate mass which is representative of the batch and intended for laboratory analysis. The quantity taken for each sample is $1500 \mathrm{~mL}$. This experiment lasted four weeks (maximum time of exposure of the oils by the trad- 
ers.) Every week, approximately $250 \mathrm{~mL}$ of palm oil are taken for the chemical analyzes such as the determination of the indices of acid, of iodine and peroxide as well as the dosage of vitamins $\mathrm{A}$ and $\mathrm{E}$. These analyzes allowed to determine the levels of free fatty acids, unsaturated fatty acids, peroxides and to define the losses in vitamins $\mathrm{A}$ and $\mathrm{E}$ during the solar exposure of red and refined palm oils.

\subsubsection{Acid Index}

The acid number was determined according to the method described by NF ISO 1242: $1999 \mathrm{~T} 75-103$. The acid number of a fat is the number of $\mathrm{mg}$ of potassium hydroxide (KOH) required to neutralize the free fatty acids (FFA) contained in 1 $\mathrm{g}$ of fat. It measures the amount of FFA present in fat. The principle consists of dissolving the fat in neutralized hot ethanol and then titrating the FFA present with a standard solution of $\mathrm{KOH}$ in the presence of phenolphthalein as an indicator. A quantity of $7 \mathrm{~g}$ of fat was weighed and introduced into a flask or conical flask. A volume of 50 to $70 \mathrm{~mL}$ of previously neutralized hot alcohol $\left(36^{\circ} \mathrm{C}\right)$ and 2 drops of colored indicator were added. This set was titrated with potassium hydroxide $(1 \mathrm{~N})$ stirring vigorously until persistent pink coloring for 30 seconds. The result is as follows:

$$
I_{a}=(V * 56.1 * N) / m
$$

where:

$V$ : volume of potash in $\mathrm{mL}$,

$N$ : normality of the potash solution,

$m$ : mass of the test sample in $\mathrm{g}$,

$56.1 \mathrm{~g}$ : relative molecular mass of $\mathrm{KOH}$.

The acid number is expressed in $\mathrm{mg} \mathrm{KOH} / \mathrm{g}$ oil.

\subsubsection{Iodine Index}

Iodine index $\left(I_{i}\right)$ is the number of grams of iodine fixed per $100 \mathrm{~g}$ of oil. It was determined according to ISO 3961/1996. Its principle is to make a solution react the Wijs reagent on the fat dissolved in chloroform. A solution of potassium iodide is then added to the mixture to extract the iodine in the aqueous phase which is back titrated with a solution of sodium thiosulfate. A mass of $0.25 \mathrm{~g}$ of oil was dissolved with $20 \mathrm{~mL}$ of chloroform $\left(\mathrm{CCl}_{4}\right)$ in a $250 \mathrm{~mL}$ Erlenmeyer flask. Then $25 \mathrm{~mL}$ of Wijs reagent was added thereto. The Erlenmeyer flask was plugged, stirred and left in the dark for 1 hour. A blank test was prepared by replacing the sample with distilled water. Then, $20 \mathrm{~mL}$ of potassium iodide (1\%) and $150 \mathrm{~mL}$ of distilled water were added thereto respectively. Then the released iodine was titrated with sodium thiosulfate. When the solution is partially discolored, 3 drops of starch paste (1\%) are added and the solution is titrated until colorless. At equivalence, the solution turns from blue to colorless. The result is expressed as follows:

$$
I_{i}=127 * C *\left(V_{0}-V\right) / 10 * m
$$


where:

$V_{0}$ : volume in $\mathrm{mL}$ of thiosulphate used for the blank test,

$V:$ volume in $\mathrm{mL}$ of thiosulphate used for the test portion,

$C: \mathrm{mol} / \mathrm{L}$ concentration of thiosulphate used,

$m$ : mass in $\mathrm{g}$ of the test,

127: molar mass in $\mathrm{g} / \mathrm{mol}$ of iodine (I),

The iodine value is expressed in $\mathrm{g}$ of Iodine/ $100 \mathrm{~g}$ fat.

\subsubsection{Peroxide Index}

The peroxide number was determined according to the method described by AFNOR NF T 60-220. This is the amount of peroxide present in the sample, expressed in milliequivalents of active oxygen contained in one kilogram of product, oxidizing potassium iodide with release of iodine. The principle is based on the titration of the iodine liberated by a solution of sodium thiosulfate $\mathrm{Na}_{2} \mathrm{~S}_{2} \mathrm{O}$. About $1 \mathrm{~g}$ of oil was weighed in a flask to the nearest $0.001 \mathrm{~g}$ and mixed with 10 $\mathrm{mL}$ of chloroform; everything is agitated. $15 \mathrm{~mL}$ of glacial acetic acid and $1 \mathrm{~mL}$ of potassium iodide at $10 \%$ are added thereto. The mixture is stirred for 1 minute and left standing for 5 minutes in the dark and at a temperature of 15 to $25^{\circ} \mathrm{C} .75$ $\mathrm{mL}$ of distilled water are added followed by a titration of the liberated iodine with a solution of sodium thiosulfate $\left[\mathrm{C}\left(\mathrm{Na}_{2} \mathrm{~S}_{3} \mathrm{O}\right)\right]$ at $0.01 \mathrm{~N}$ with vigorous stirring and using the starch solution 1 "g/100mL" as an indicator. A blank test is performed simultaneously. The peroxide index in milliequivalent of $\mathrm{O}_{2} / \mathrm{kg}$ is calculated according to the equation:

$$
I_{p}=10 \times \frac{V-V_{0}}{m}
$$

where:

$m$ : mass of the test portion in grams,

$V$ : volume of solution of sodium thiosulfate poured expressed in $\mathrm{mL}$,

$V_{0}$ : volume of sodium thiosulfate solution for the blank test in $\mathrm{mL}$.

\subsubsection{Extraction and Dosage of Vitamins $A$ and $E$}

The conditions were the same for both vitamins unlike detection wavelengths. The separation of vitamins A and E was performed by Ultra High Performance Liquid Chromatography. The election of vitamins $\mathrm{E}$ and A was carried out using a methanol binary mixture (99\%). U.V. detection was carried out at $325 \mathrm{~nm}$ for vitamin A and $292 \mathrm{~nm}$ for vitamin E. These analyzes were carried out in accordance with Directive 2000/45/EC of the Commission of 06 Juliet 2000.

- Saponification

To the nearest $0.1 \mathrm{~g}, 50 \mathrm{~g}$ of sample were weighed and transferred to a 1-liter conical flask. Then, $200 \mathrm{~mL}$ of ethanol (95\%) were added. The contents of the flask were stirred at 100 revolutions per minute $\left(20^{\circ} \mathrm{C}\right)$ to disperse the sample. Then, $2 \mathrm{~mL}$ of sodium ascorbate " $100 \mathrm{~g} / \mathrm{L}$ " and $50 \mathrm{~mL}$ of potassium hydroxide solution "500 g/L" were added to the mixture. A reflux condenser was fitted to the flask and the flask was immersed in a boiling water bath for 60 minutes. 
Then, the flask was cooled to room temperature as quickly as possible under a stream of cold water.

- Extraction of vitamins A and E

The contents of the flask were transferred to an extraction test tube. The flask was rinsed with two $25 \mathrm{~mL}$ fractions of ethanol (95\%) and the rinses were transferred to the test tube. Similarly, the flask was rinsed with two fractions of 125 $\mathrm{mL}$ of petroleum ether (having a boiling point between $40^{\circ} \mathrm{C}$ and $60^{\circ} \mathrm{C}$ ) and a fraction of $250 \mathrm{~mL}$ of distilled water, transferring each rinses in the test tube. The sample was plugged and shaken well for $1 \mathrm{~min}$, while releasing the pressure from time to time. The test specimen was kept at rest while waiting for the separation of the two liquid phases before removing the cap. Once the phases are separated, the walls of the test tube are washed with a few milliliters of petroleum ether. A slight pressure of inert gas was applied to the side tubing and the upper phase of petroleum ether was transferred to a separatory funnel. An amount of $125 \mathrm{~mL}$ of petroleum ether was added to the specimen container and then capped and shaken for $1 \mathrm{~min}$. After decantation, the upper phase was transferred to the separating funnel as before; this action was repeated again. The combined petroleum ether extracts were washed with four $100 \mathrm{~mL}$ portions of distilled water by inverting the device first gently and then stirring slowly to minimize emulsion formation. The washed extract was transferred through medium/fast filtration paper containing $60 \mathrm{~g}$ of anhydrous sodium sulfate in a suitable vacuum evaporation vial. The separatory funnel was rinsed with two $20 \mathrm{~mL}$ portions of petroleum ether and the rinses were transferred to the evaporation vial through the filter. The filter was washed again with two $25 \mathrm{~mL}$ portions of petroleum ether and the rinses were collected in the evaporation flask. The ether extract was evaporated to dryness under vacuum at a temperature not exceeding $40^{\circ} \mathrm{C}$.

- Determination of vitamins A and E by Ultra High Performance Liquid Chromatography.

The residue was dissolved in a minimum volume of methanol and transferred quantitatively into a $20 \mathrm{~mL}$ volumetric flask. The evaporation flask was rinsed with three small portions of methanol, transferring the flushing liquid to the volumetric flask. The volume was completed with methanol and mix. The extract was filtered through a filtration membrane " $0.45 \mu \mathrm{m}$ ". A volume of $0.8 \mu \mathrm{l}$ of sample extract was injected into the column of the chromatograph equipped with a pump set to provide a constant flow rate of $1 \mathrm{~mL} / \mathrm{min}$ and a column "acquity UPLC R BEHC181.7 $\mu \mathrm{m}$ ". The average peak area was calculated from two injections of the sample extract. Determination of the retinol and tocopherol concentration of the extract was based on the mean peak area of two standard injections of similar concentration. Injections were alternated with sample extract and standard solution. The quantification of vitamins $\mathrm{A}$ and $\mathrm{E}$ each week made it possible to determine the vitamin $\mathrm{A}$ and $\mathrm{E}$ losses of palm oils exposed to solar radiation according to the following equation: 
Vitamin $\operatorname{loss}(\%)=\frac{\text { Amount of votamin } W 0-\text { Amount of vitamin } W_{n}}{\text { Amount of vitamin } W 0} \times 100$

where:

$W=$ week,

$W 0=$ week of purchase,

$n=1,2,3$ and 4 .

All chemicals used in this study were of analytical grade. Sodium ascorbate, phenolphthalein, and starch were from Merk, (Germany).

Glacial acetic acid, potassium hydroxide and methanol were supplied by prolabo (France).

As for the Wijs reagents, the potassium iodide and sodium thiosulfate used were from the suppliers pancreac (Germany), Scharlau (Spain) and Chem-Lab (Belgium) respectively.

Ethanol, and standards (retinol acetate, $\alpha$-tocopherol) are from Sigma-aldrich (Germany).

The solvents hexane, chloroform, petroleum ether are from Carlo Erba (France), chem-Lab (Belgium).

All tests were performed in triplicate.

\subsubsection{Statistical Analysis}

Data was statistically analyzed using Statistical Package version 7.1. The level of significant difference was determined at $\mathrm{P}=0.05$.

\section{Results and Discussion}

\subsection{Evaluation of the Concentrations of Free Fatty Acids, Unsaturated Fatty Acids and Peroxides of red and Refined Palm Oils Exposed to Sunlight During Sale}

Figure 1 shows changes in the levels of free fatty acids, unsaturated fatty acids and peroxides in red and refined palm oils exposed to sunlight during sales. The levels of free fatty acid are ranged from 0.89 to $17.14 \mathrm{mg} \mathrm{KOH} / \mathrm{g}$ from the day of purchase of palm oils $(W 0)$ at the fourth week $(W 4)$ of solar exposure (Figure $1(\mathrm{~A})$ ). The acid value of red palm oil was higher on purchase. During the four weeks of solar exposure, the free fatty acid content of protected and unprotected red and refined palm oils increased gradually. However, this increase in free fatty acid content was lower with the samples oils protected with aluminum foil "1.44 - $5.17 \mathrm{mg} \mathrm{KOH} / \mathrm{g}$ " than the unprotected ones " 0.89 - $17.14 \mathrm{mg} \mathrm{KOH} / \mathrm{g}$ ". Figure 1 (B) analysis indicates that iodine values for red and refined palm oils samples protected and unprotected with foil paper ranged from 95.11 to $3.22 \mathrm{~g} \mathrm{I} / 100 \mathrm{~g}$. Iodine indices of protected and unprotected red and refined palm oils samples decreased during the four weeks of sun exposure. At the fourth week of experiment, iodine values of different oils were less than $10 \mathrm{~g} \mathrm{I}_{2} / 100 \mathrm{~g}$ except for protected and unprotected red palm oil samples with 18.11 and $12.84 \mathrm{~g} \mathrm{I}_{2} / 100 \mathrm{~g}$. Figure $1(C)$ shows the change in peroxide levels in red and refined palm oils exposed to sunlight. Formation of peroxides in red and refined palm oil samples 


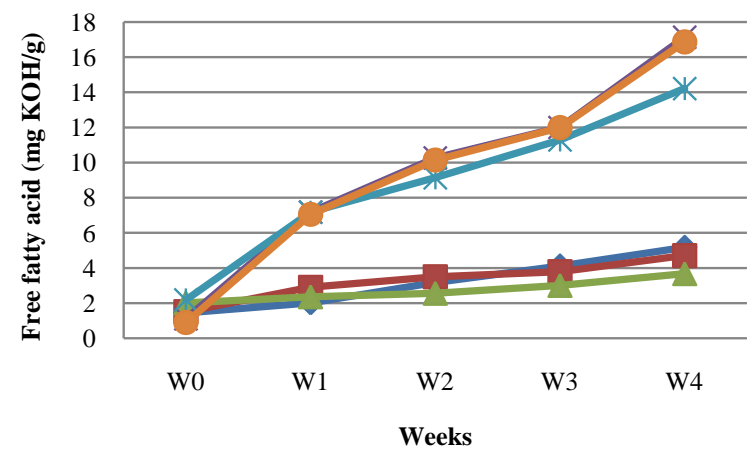

(A)

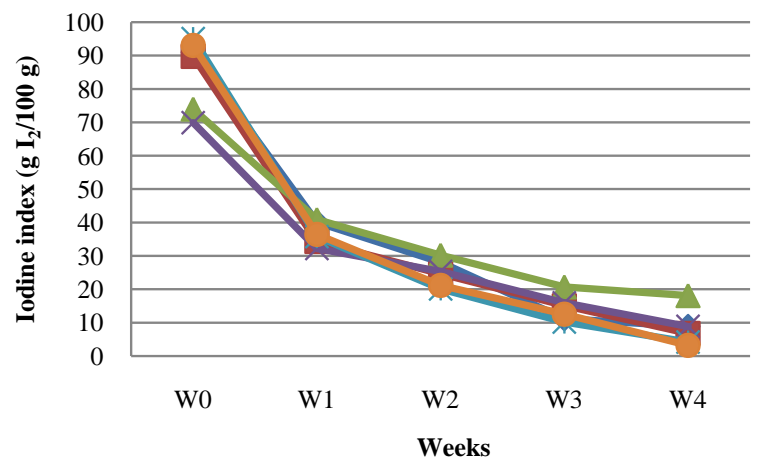

(B)

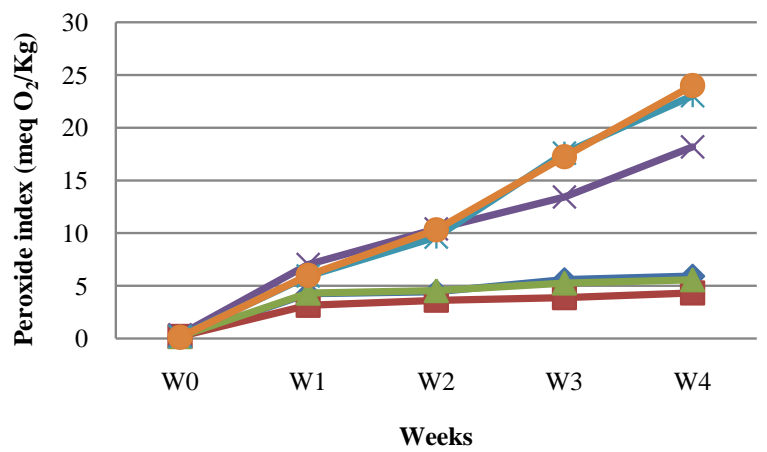

(C)

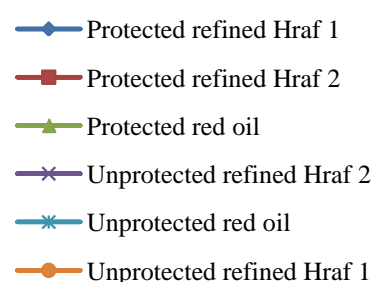

$\longrightarrow$ Protected refined Hraf 1

$\longrightarrow$ Protected refined Hraf 2

$\_$Protected red oil

$\longrightarrow$ Unprotected red oil

*-Unprotected refined Hraf 2

—- Unprotected refined Hraf 1

$\longrightarrow$ Protected refined Hraf 1

$\longrightarrow$ Protected refined Hraf 2

$\longrightarrow$ Protected red oil

$\leftarrow$ Unprotected red oil

* Unprotected refined Hraf 2

Unprotected refined Hraf 1

Figure 1. Variation of acid, iodine and peroxide indices of red and refined palm oils during solar exposure ((A) Variation of free fatty acid; (B) Variation of iodine index; (C) Variation of peroxide values).

unprotected by aluminum foil was faster than the protected ones. At week 0 $(W 0)$ all the oils contained $0.11 \pm 0.10$ to $0.34 \pm 0.08$ meq $0_{2} / \mathrm{kg}$ of fat. Already in first week of exposure $(W 1)$, the amounts of peroxide increased in protected and unprotected palm oil samples and ranged from $3.15 \pm 0.01$ to $4.24 \pm 0.04 \mathrm{meq}$ $\mathrm{O}_{2} / \mathrm{kg}$ for protected oil samples and $5.93 \pm 0.07$ to $7.02 \pm 0.12$ meq $\mathrm{O}_{2} / \mathrm{kg}$ for unprotected samples. Refined palm oil Hraf 2 with the foil-protected container "3.15 $\pm 0.01 \mathrm{meq} \mathrm{O}_{2} / \mathrm{Kg}$ " had the lowest peroxide content and unprotected red palm $\left(7.02 \pm 0.12 \mathrm{meq} \mathrm{O}_{2} / \mathrm{kg}\right)$ had the highest content in the first week $(W 1)$ of exposure. These proportions of peroxides gradually increased with the duration of exposure until the fourth week. However, rates were lower with protected palm oil samples " $4.32 \pm 0.15-5.91 \pm 0.06 \mathrm{meq} \mathrm{O}_{2} / \mathrm{kg}$ " than unprotected sam- 
ples " $18.19 \pm 0.02-24.00 \pm 0.03$ meq $\mathrm{O}_{2} / \mathrm{Kg}$ ". By the fourth week (W4), the refined palm oil Hraf 2 sample protected with aluminum foil had the lowest peroxide content " $4.32 \pm 0.15$ meq $\mathrm{O}_{2} / \mathrm{Kg}$ " and the refined palm oil Hraf 1 sample unprotected had the highest quantity " $24.00 \pm 0.03 \mathrm{meq} \mathrm{O}_{2} / \mathrm{kg}$ ".

The analysis of the results highlights an increase of free fatty acid, peroxide and a reduction of unsaturated fatty acids proportion (iodine value) in samples of protected or unprotected palm oils solar rays. Indeed, these different indices make it possible to evaluate the state of freshness and the organoleptic quality of oil. Thus, red and refined palm oils samples exposed to the sun's rays undergo degradation very quickly except those with containers protected with foil sheets. However, the formation of peroxide in unprotected palm oils samples is less alarming than that of sunflower, rapeseed and soybean oil determined by Sohail et al. (2010). According to his work, the peroxide content of sunflower, rapeseed and soybean oils exposed to solar radiation for four weeks was around 100 me$\mathrm{qO}_{2} / \mathrm{kg}$. This difference in peroxide content is due to the fact that sunflower oil contains more unsaturated fatty acids. However, free fatty acid levels of sunflower, rapeseed and soybean oils are lower than those of protected or unprotected red and refined palm oils with values of less than $5 \%$ free fatty acids in four weeks of solar exposure [6]. Indeed, the oils can oxidize in the presence of oxygen and certain factors (UV, water, heat, traces of metals, ...) [7]. This oxidation, called autooxidation or aldehyde rancidity, leads initially to the formation of peroxides (or hydroperoxides) by fixing one mole of oxygen on the carbon located in position a relative to an ethylenic bond of the unsaturated fatty acids constituting the glycerides [8]. To evaluate the first stages of this oxidation, the peroxide index is measured [9]. This difference in proportions of free fatty acid could also be explained by the action of lipases which would be pronounced in palm oils as in sunflower, rapeseed and soybean oils. Reduction of iodine index content of palm oil from 95.11 to $3.22 \mathrm{~g} \mathrm{I} / 100 \mathrm{~g}$ is due to oxidation of unsaturated fatty acid caused by sun rays. According to Belitz and Grosch (1987) [10], the oxidative stability of lipids is mainly determined by the degree of unsaturation of fatty acids.

\subsection{Vitamin A}

With regard to vitamin A loss rates, they are shown in Figure 2. This figure reveals that vitamin A losses become more and more important as exposure time goes on. In addition, these loss rates are higher for the palm oils samples contained in packages not covered with aluminum foil. They are respectively $89.47 \%$; 93.67\% and 94.49\% for red, refined Hraf 1 and rafined Hraf 2 palm oil. For palm oils whose containers were protected with aluminum foil, vitamin A losses ranged from $18.80 \%$ to $58.30 \%$. This indicates a deterioration of more than half of their vitamin A content after four weeks of sun exposure.

\subsection{Vitamin E}

As for Figure 3, it shows the vitamin E loss rates of the red and refined palm oils 


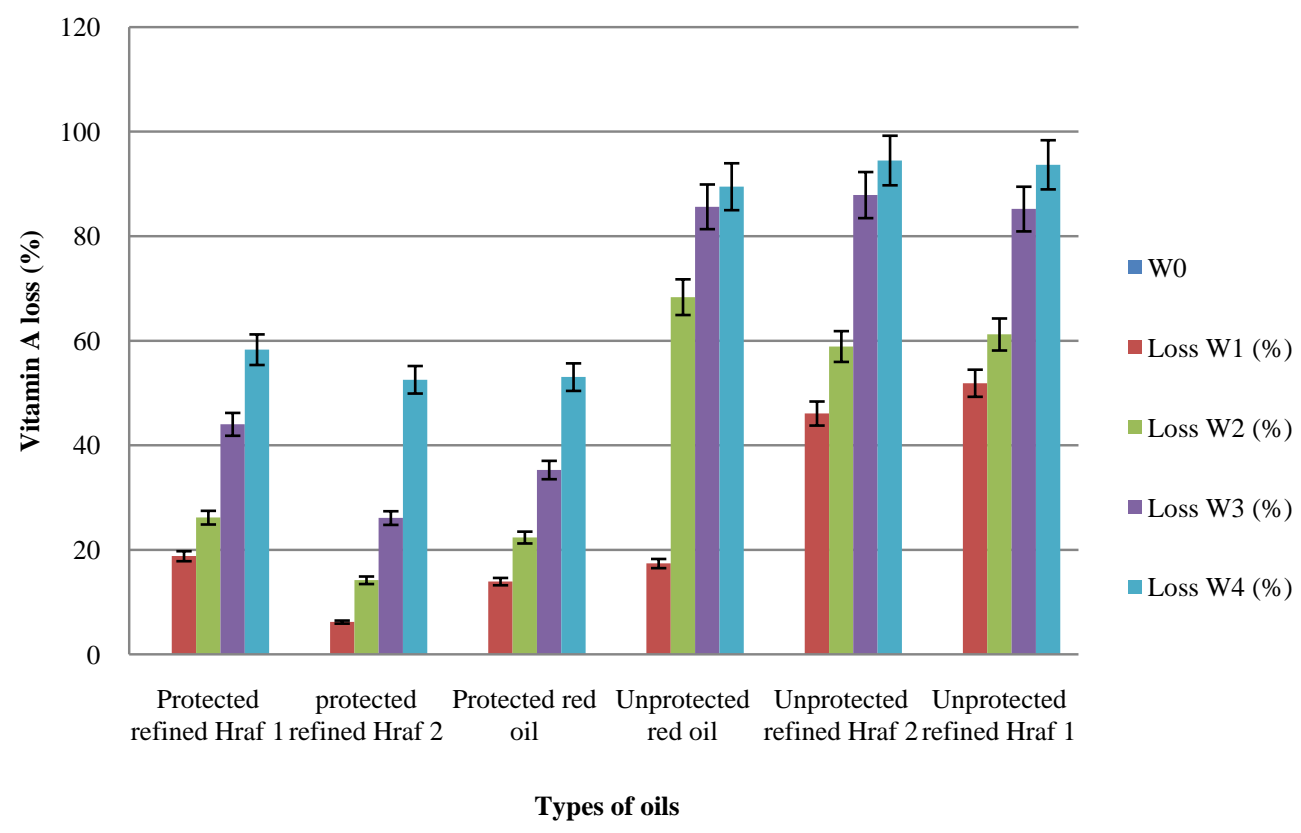

Figure 2. Distribution of vitamin A losses of oils during four weeks of solar exposure.

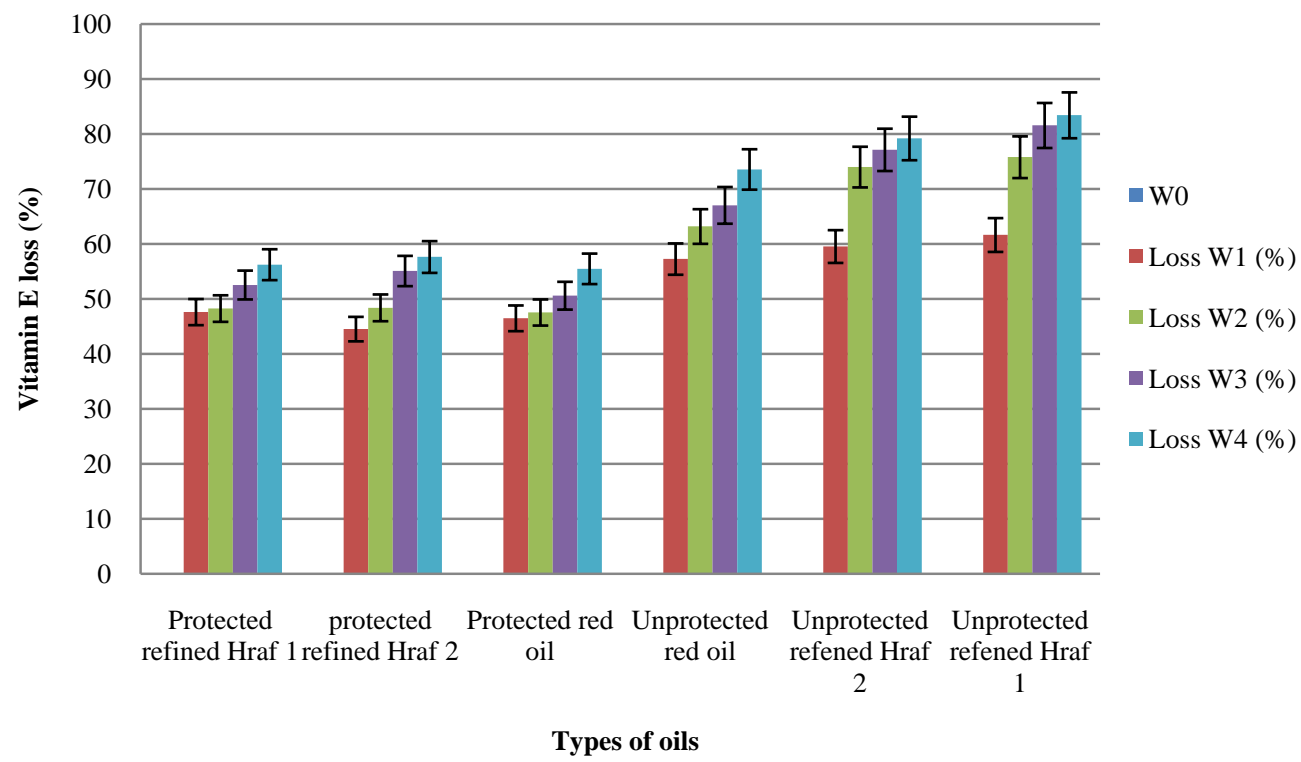

Figure 3. Distribution of vitamin E losses from oils during four weeks of solar exposure.

as a function of the exposure time. The vitamin $\mathrm{E}$ losses of red and refined palm oils were very high in the first week of solar exposure. These sharp losses ranged from $44.53 \%$ to $61.65 \%$ for protected and unprotected oils. But from the second to the fourth week, these losses increased slowly and reached about $60 \%$ for protected oils and $80 \%$ for unprotected ones.

Vitamin A and E losses of exposed palm oil with containers protected with aluminum foil are lower than unprotected because outer protection reduces the effect of sunlight degradation. Indeed, most vitamins are very unstable compounds that are quickly broken down due to their sensitivity to certain elements 
such as oxygen and solar radiation [11]. Generally, vitamin E protects unsaturated fatty acids from the oxidation effect [12]. However, in this study, the vitamin $\mathrm{E}$ contained in the palm oils undergo a strong degradation from the first week of solar exposure. These losses could be explained by the fact that vitamin E, through its antioxidant effect, captures the free radicals formed by the oxidation of mono and polyunsaturated fatty acids due to the action of solar rays. Thus, this oxidized vitamin E will not be detectable during the assay. The amount of vitamin $\mathrm{E}$ in the oil depends not only on the presence of these compounds in the fruit but also other involved factors including variety and maturity [13] as well as the conditioning and duration of the conservation [14] [15].

\section{Conclusion}

At the end of this study, it should be noted that red and refined palm oils have several chemical parameters that determine their quality. In this study, the chemical parameters sought are: the acid, iodine and peroxide index, the vitamins $\mathrm{A}$ and $\mathrm{E}$ content. The determination of these different parameters allowed us to assess the quality of these different types of palm oilsanalized. Red and refined palm oils are important sources of nutrients such as unsaturated fatty acids, vitamins $\mathrm{A}$ and $\mathrm{E}$. But the exposure to sunlight greatly reduces the nutritional quality of these oils. Therefore, it is imperative to educate traders to prohibit the sale of palm oils in conditions exposing these products directly to the sun. It is also necessary for the palm oil refining industries to indicate on the containers: "to keep sheltered from the sun's rays". In addition, the quality of palm oil containers needs to be improved in order to condition these oils in solar-proof containers so as to maintain their nutritional qualities.

\section{Conflicts of Interest}

The authors declare no conflicts of interest regarding the publication of this paper.

\section{References}

[1] Jacquemard, J.-C. (2012) The Oil Palm. Tropical Agricultures Book in Hand, Éditions Quæ, CTA, Gembloux Agricultural Press, Gembroux, 240 p.

[2] Hoyle, D. and Levang, P. (2012) Development of Palm Oil in Cameroon. Report of April 12 by WWF, IRD, CIFOR, $16 \mathrm{p}$.

[3] Platts, M. and Leong, Y. (2019) Achieving High Soil Fertility, Efficient Fruit Harvesting and Low Carbon Footprint Palm Oil Production in Malaysia. Agricultural Sciences, 10, 1396-1403. https://doi.org/10.4236/as.2019.1010102

[4] Sundram, K., Sambanthamurthi, R. and Tan, Y. (2003) Palm Fruit Chemistry and Nutrition. Asia Pacific Journal Clinic al Nutrition, 12, 355-362.

[5] Wong, R. and Radhakrishnan, A. (2012) Tocotrienol Research: Past into Present. Nutrition Review, 70, 483-490. https://doi.org/10.1111/j.1753-4887.2012.00512.x

[6] Sohail, M., Ahmed, T., Akhtar, S. and Durrani, Y. (2010) Effect of Sunlight on Quality and Stability of Dietary Oils and Fats. Pakistan Journal of Biochemistry 
Molecular Biology, 43, 123-125.

[7] Judde, A. (2004) Prevention of Fatty Acid Oxidation in a Cosmetic Product: Mechanisms, Consequences, Means of Measurement, Which Antioxidants for Which Applications. $O C L, 11,414-418$. https://doi.org/10.1051/ocl.2004.0414

[8] Choe, E. and Min, D. (2006) Mechanisms and Factors for Edible Oil Oxidation. Comprehensive Reviews in Foods Science and Food Safety, 5, 170-186. https://doi.org/10.1111/j.1541-4337.2006.00009.x

[9] Gharby, S., Harhar, H., Bouzoubaa, Z., Roudani, Z., Chafchaouni, I., Kartah, B. and Charrouf, Z. (2014) Effect of Polyphenols Polyphenols Extracted from Vegetable Waters on Stability of Sunflower Oil (Effect of Polyphenols Extracts from Margins on the Stability of Sunflower Oil). Journal Materiel about Science, 5, 2464-2469.

[10] Belitz, D. and Grosch, W. (1987) Food Chemistry. 2nd Edition, Springer Verlag, Berlin, $41 \mathrm{p}$.

[11] Vanbrabant, M. (2012) Vitamins. Labinfo, Report, 7-11.

[12] Bührer-astfalk, E. (2012) Vitamin E ... and the Usefulness of Supplementation. Report, $4 \mathrm{p}$.

[13] Aparicio, R. and Luna, G. (2002) Characterization of Monovarietal Virgin Olive Oils. European Journal of Lipid Scence and Technology, 104, 614-627.

https://doi.org/10.1002/1438-9312(200210)104:9/10<614::AID-EJLT614>3.0.CO;2-L

[14] Psomiadou, E., Tsimidou, M. and Boskou, D.A. (2000) Tocopherol Levels of Greek Virgin Olive Oils. Journal of Agriculture and Food Chemistry, 48, 1770-1775. https://doi.org/10.1021/jf9909930

[15] Guilland, J. (2003) Repairing Vitamins in Nature. Vitamins in Agrifood Industries. Technical and Documents Edition, 25-56. 